\title{
Diffuse Idiopathic Skeletal Hyperostosis Interfering with Ankylosing Spondylitis: A Case Report
}

\section{Diffuz İdiopatik Skeletal Hiperostoz ile Karışan Ankilozan Spondilit: Olgu Sunumu}

\section{Ozgur TASPINAR 1 , Teoman AYDIN, Muge KEPEKCI느, Celaleddin PERU², Hakan SEYITHANOGLU³ \\ ${ }^{1}$ Department of Physical Medicine and Rehabilitation, Bezmialem Vakif University, Istanbul, Turkey \\ ${ }^{2}$ Department of Internal Diseases, Bezmialem Vakif University, Istanbul, Turkey \\ ${ }^{3}$ Department of Neurosurgery, Bezmialem Vakif University, Istanbul, Turkey}

\section{ABSTRACT}

Ankylosing spondylitis is the axial skeleton and sacroiliac crick, starting in late adolescence or early adulthood age, and is characterized by spondyloarthropathy. Some symptoms are confused with diffuse idiopathic skeletal hyperostosis. Our case had neck, back, waist, and heel pain and morning stiffness lasting about half an hour and was admitted with complaints. Lateral lumbar spine radiographs taken at the corners of the lumbar vertebral bodies compatible with DISH consecutive osteophytes were detected, and radiography of the calcaneus of the lateral foot showed hyperostosis compatible with DISH. However, the patient was diagnosed with ankylosing spondylitis because of a bilateral crick in the sacroiliac radiography. In this case-a differential diagnosis between DISH and ankylosing spondylitisclinical and radiological features were assessed by reviewing the literature.

Key Words: Ankylosing spondylitis, diffuse idiopathic skeletal hyperostosis, hyperostosis

\section{ÖZET}

Ankilozan spondilit, geç adolesan veya erken erişkin dönemde başlayan, aksiyel iskelet ve sakroiliak tutulumla karakterize bir spandiloartropatidir. Bazı olgular Diffuz idiopatik skeletal hiperostoz (DISH) ile karıştırılmaktadır. Olgumuz, boyun, sırt, bel, topuk ağrısı ve yaklaşık yarım saat süren sabah tutukluğu şikayetleriyle başvurdu. Çekilen lomber lateral grafide lomber vertebra korpus köşelerinde DISH ile uyumlu akıcı osteofitler saptandı ve ayak lateral grafide kalkaneus bölgesinde DISH ile uyumlu hiperosteoz görüldü. Ancak sakroiliak grafide bilateral tutulumdan dolayı hastaya ankilozan spondilit tanısı konuldu. Bu olgu sunumunda, DISH ve ankilozan spandilitin ayırıcı tanısı, klinik ve radyolojik özellikleri literatür eşliğinde gözden geçirilerek değerlendirildi.

Anahtar Sözcükler: Ankilozan spondilit, diffuz idiopatik skeletal hiperostoz, hiperostoz

\section{Giriş}

Ankilozan Spondilit (AS) ve Diffüz İdiopatik Skeletal Hiperostoz (DISH) vakaları bazen klinesyenler tarafından karıştırılabilmektedir. Sunduğumuz AS olgumuzda bu iki hastalığın ayırıcı tanısındaki farklılıkları tanımlamaya çalışacağız.

Ankilozan Spondilit tipik omurga ve sakroiliak eklem, periferik eklemleri, entez yerlerini etkileyen, iltihabi, kronik, multisistemik bir bozukluktur. Başlangıç belirtiler genç erişkin dönemde görülür. Kırkı geçen yaşlarda ender olarak başlar. Hastalık aktivitesi hafif aktiviteli veya aktivite durumunun süreklilik oluşturduğu, ilerleyici bir hastalık süreciyle seyredebilir (1). DISH ise sıklıkla erişkin, ileri yaş erkeklerde saptanan hiperostoz durumudur. Sakroiliak enflamasyon ve disklerde patoloji olmadan en az dört omur seviyesinde yeni kemik oluşumunun gösterilmesi tanısaldır. Patoloji, entez bölgesinin tutulumundan sonra ligamanlardaki akıcı osteofitlerle devam eder. Sıklıkla omurgada kısıtlılık oluşur. (2). Başlangıcı ileri yaş olması, geniş ve akıcı ligamentöz ossifikasyonların olması, sakroileit bulunmaması ve HLA-B27 negatifliği DISH’in AS'den farkılılıklarıdır.

Biz de daha önce DISH tanısıyla takip edilen ancak klinik ve radyografik olarak Ankilozan Spondilit tanısı koyduğumuz 54 yaşındaki bir erkek olgumuzu sunuyoruz. 


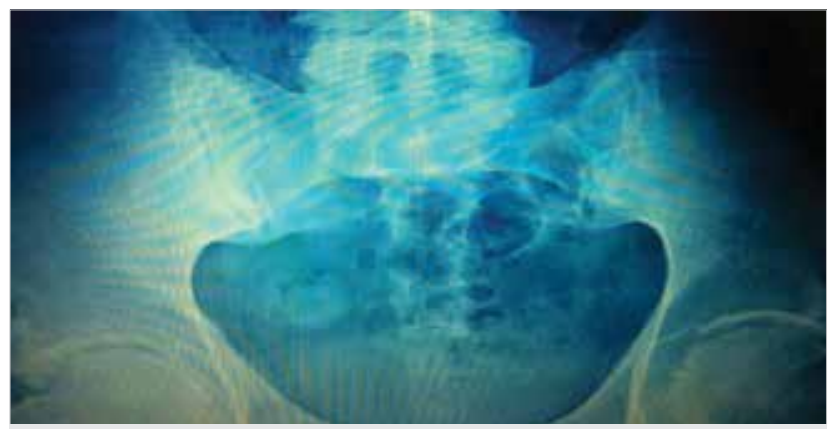

Resim 1. Sakroiliak eklemde diffuz daralma

\section{Olgu Sunumu}

Elli dört yaşında erkek hasta yaklaşık 10 yıldır bel, sırt ve boyunda ağrı ve sabah tutukluğu şikayetiyle polikliniğimize başvurdu. Hastanın ağrıları istirahat ile artıyor, aktiviteyle azalıyordu ve $40 \mathrm{dk}$ süren sabah tutukluğu mevcuttu.

Hastanın sistemik muayenesi normaldi. Kas iskelet sistemi muayenesinde, boyun antefleksiyonda, torakal kifoz artmış, lomber bölge fleksiyonda idi. Lomber, dorsal ve servikal omurga bölgelerinde eklem hareket açıklığı her yöne kısıtlı idi. El parmak zemin mesafesi $22 \mathrm{~cm}$, oksiput-duvar mesafesi $6 \mathrm{~cm}$, göğüs ekspansiyonu $4 \mathrm{~cm}$, modifiye Schober testi $2 \mathrm{~cm}$ olarak ölçüldü. Laboratuar değerlendirmesinde eritrosit sedimantasyon hızı (ESH) $23 \mathrm{~mm} / \mathrm{saat}$, C-reaktif protein (CRP) $0,5 \mathrm{mg} / \mathrm{dL}$, romatoid faktör (RF) negatif, HLA-B27 negatif, açlık kan şekeri, karaciğer ve böbrek fonksiyon değerleri normal saptandı. AS düşünülen hastadan lomber grafisi, sakroiliak eklem grafileri ve topuk ağrısından dolayı ayak AP/lat grafileri istendi. Hastada sakroiliak eklemlerde diffüz daralma (Resim 1) saptandı. Lomber grafide vertebra korpus köşelerinde disk mesafesine uzanmayan akıcı osteofitler (Resim 2) görüldü. Ayak kalkaneus bölgesinde hiperostoz (Resim 3) görüldü. Ayırıcı tanı açısından istenen sakroiliak bilgisayarlı tomografi' de (BT) bilateral sakroiliak eklemlerde erozyon ve daralma saptandı (Resim 4).

Hastada AS düşünüldü. Indometazin 500 mg. $2 \times 2$ başlandı. Ekstansiyon egzersizleri, germe egzersizleri ve solunum egzersizleri önerildi. Romatoloji polikliniğinden takibe alındı. Hastadan bilgilendirilmiş onam alınmıştır.

\section{Tartışma}

Ankilozan spondilit (AS), idyopatik, genetik yatkınlığı olan, omurga eklemlerinde ve çevre yapılarda iltihabi reaksiyon yapan, spinal kolonda ilerleyici kemik füzyona neden olan kronik, iltihabi, romatizmal durumdur. Kalça ve omuz eklemleri hastaların $1 / 3$ ünde tutulur. AS hastalarının çoğunda HLA-B27 pozitiftir $(1,3)$. AS'de başlangıç semptomları genellikle genç erişkin dönemde başlar. Kırk yaş üstünde başlangıç enderdir. İlk semptom genelde sinsi başlayan hareketle azalan bel ağrisı ve tutukluktur. AS'nin radyolojik bulgular1 omurgada, entez yerleşimlerindedir. AS'nin ilk saptanan radyolojik bulgusu sakroileittir. Genellikle çift taraflıdır.

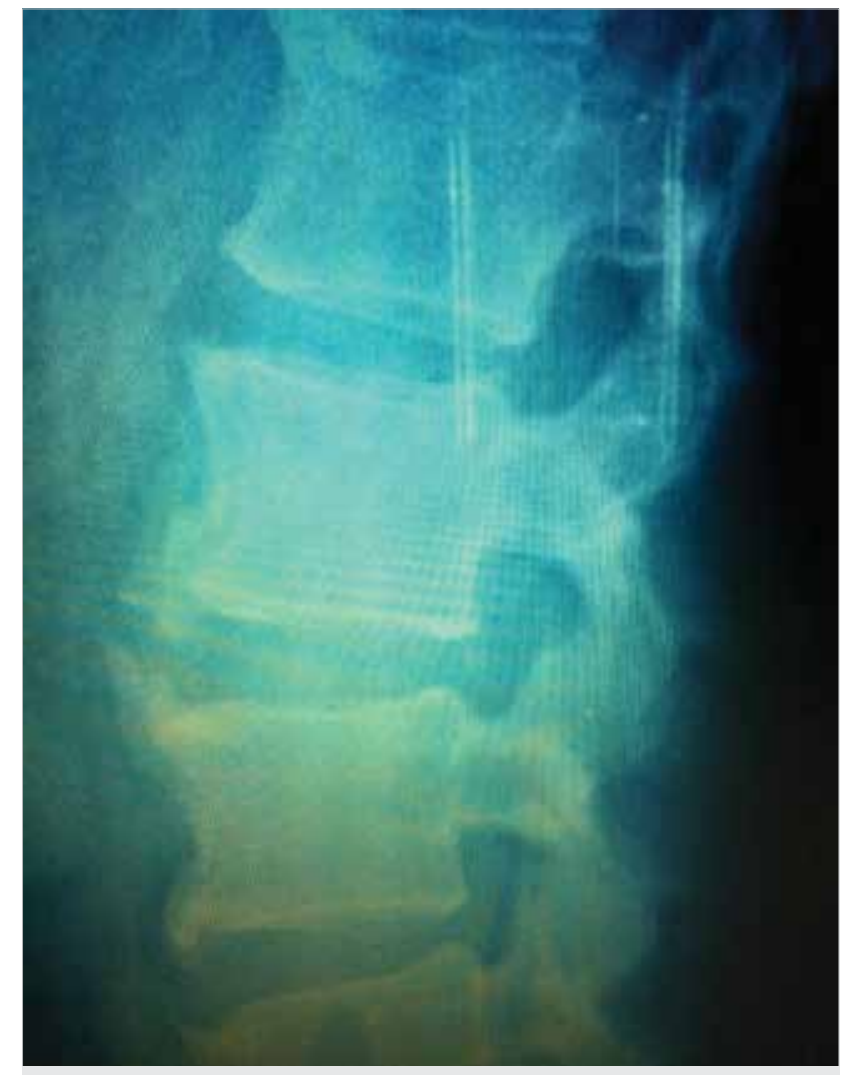

Resim 2. Vertebra korpus köşelerinde DISH ile uyumlu akıcI osteofitler DISH: diffuse idiopathic skeletal hyperostosis

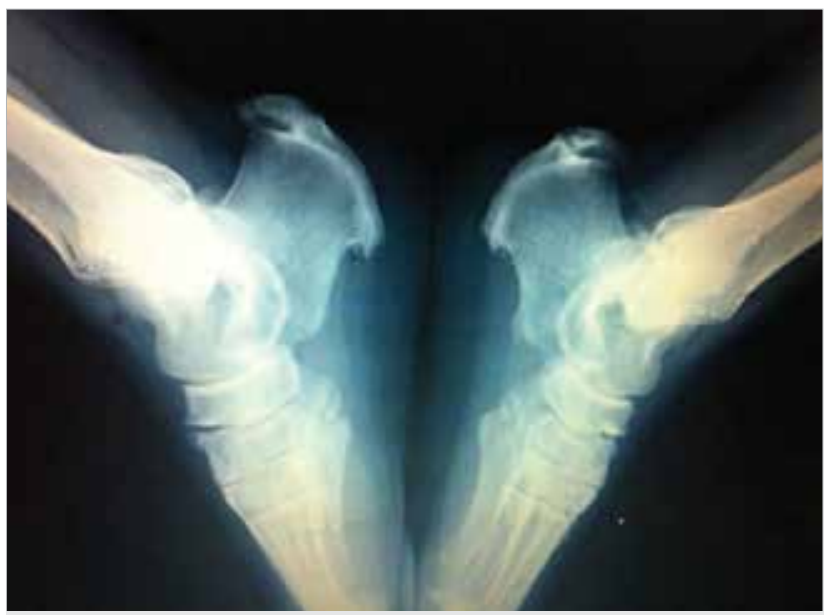

Resim 3. Ayak kalkaneus bölgesinde DISH ile uyumlu hiperosteoz

DISH: diffuse idiopathic skeletal hyperostosis

Sakroileit eklemin 1/3 alt bölümünde daha çok saptanır. AS, vertebra korpuslarına tutunmuş anulus fibrosusu etkileyerek Romanus lezyonuna (parlak köşe) neden olur. Bu durum ilerleyerek vertebra kareleşmelerini oluşturur. Anulus fibrosusun dış bölgesinin aşamalı ossifikasyonuna bağlı olarak intervertebral kemiksi köprüler denilen sindesmofitler oluşur. Bunlar karşılıklı ve iki taraflıdır. Apofizyal eklemlerin füzyonu, spinal ligamanların kalsifikasyonu, iki taraflı sindesmofitler, omurgada tam füzyon meydana getirir. Bu durum omurgada 


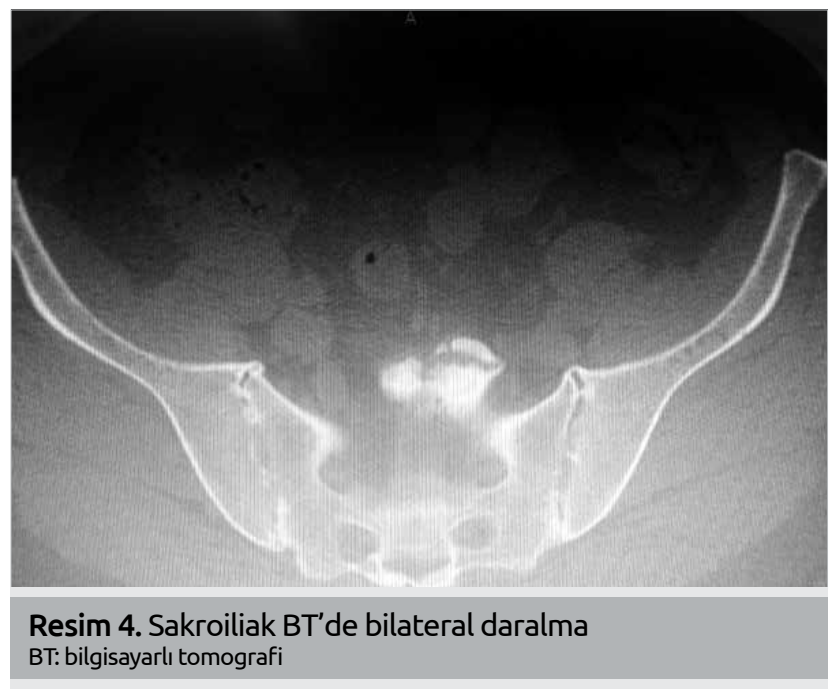

bambu kamışı manzarası denilen durumu oluşturur $(3,4)$. DISH, omurganın az görülen florid hiperostozisidir. Forestier ve Rotes-Queral bu hastalığı iyatrojenik olan kemikleşme diyatezi olarak tanımlamışlardır (2). Aşırı kilo, diabetes mellitus, gut, A vitamini seviyeleri ile DISH arasında ilişkiler saptanmıştır. Hastalığın etyopatogenezinde metabolik durumların rol oynayabileceği söylenmiştir $(5,6)$. Elli yaş üstü ve erkek olanlarda üç kat fazla görülür. Omurganın ön ve sağ lateral kesimlerindeki ossifikasyonlar tipiktir. AS genetikle ilişkili bir hastalık olmasına reğmen, DISH de genetik ilişki zayıftır. Omurgada \%97 dorsal, $\% 90$ bel, \%78 boyun omurlarında ve $\% 70$ oranında ise her üç bölgede birden görülmektedir. Bu tutulumlara bağlı DISH'de en çok görülen belirtiler omurga ağrısı, omurgada sertlik, hareket kısıtlılığı ve özofagus kompresyonuna bağlı yutma zorluğudur (7). Laboratuar değerleri normaldir. Tanı için dört ve daha fazla omur seviyesinde paravertebral ossifikasyon olması gerekir. Tanı, çoğu zaman başka bir nedenle çekilmiş olan radyografilerle konulur. Çünkü DISH genellikle semptomsuzdur. Rasnick kriterleri değerlendirilerek tanıya gidilir. Rasnick kriterleri, en az dört komşu vertebra korpusunun anterolateral bölümü boyunca akıcı ossifikasyon veya kalsifikasyon (șelale imaj1), vertebra korpusunda skleroz, primer dejeneratif disk hastalığı olmadan tutulan bölümde intervertebral disk yüksekliğinin göreceli olarak korunması ile apofizyal eklemin kemiksel ankilozu, sakroiliak eklem erozyonu, sklerozu veya intraartiküler kemiksel ankilozun olmamasıdır (9). Bu radyolojik durumların olması, HLA-B 27 ilişkisinin olmaması DISH ve AS ayırıcı tanısında önemlidir (10).

\section{Sonuç}

Olgumuzdaki hasta ileri yaşta olması, omurga hareketlerindeki kısıtllık, radyolojik bulgular olması nedeniyle ön planda DISH düşünüldü. Ancak şikayetlerin erken yaşta başlaması, sakroiliak grafi ve BT'de bilateral sakroileit saptanması nede- niyle olgu AS olarak değerlendirilmiştir. Sonuç olarak, DISH düşünülen bu tip hastalarda AS tanısı da atlanmamalıdır.

Informed Consent: Written informed consent was obtained from the patient who participated in this case.

Peer-review: Externally peer-reviewed.

Author Contributions: Concept - T.A.; Design - Ö.T.; Supervision - T.A.; Funding - C.P.; Materials - M.K.; Data Collection and/or Processing - Ö.T., H.S.; Analysis and/or Interpretation - Ö.T.; Literature Review - Ö.T.; Writing - Ö.T.; Critical Review - T.A.; Other - H.S.

Conflict of Interest: No conflict of interest was declared by the authors.

Financial Disclosure: The authors declared that this case has received no financial support.

Hasta Onamı: Yazılı hasta onamı bu olguya katılan hastadan alınmıştır.

Hakem değerlendirmesi: Dış bağımsız.

Yazar Katkıları: Fikir - T.A.; Tasarım - Ö.T.; Denetleme - T.A.; Kaynaklar - C.P.; Malzemeler - M.K.; Veri Toplanması ve/veya İşlemesi - Ö.T., H.S.; Analiz ve/veya Yorum- Ö.T.; Literatür Taraması - Ö.T.; Yazıyı Yazan - Ö.T.; Eleştirel İnceleme - T.A.; Diğer - H.S.

Çıkar Çatışması: Yazarlar çıkar çatışması bildirmemişlerdir.

Finansal Destek: Yazarlar bu olgu için finansal destek almadıklarını beyan etmişlerdir.

\section{Kaynaklar}

1. Arnett FC. Arıkylosing spondylitis. In: Koopman WJ (ed). Arthritis and allied conditions. A textbook of rheumatology. Baltimore: Williams and VVilkins 1997; 1197-1208.

2. Forestier J, Lagier R. Ankylosing hyperostosis of the spine. Clin Orthop 1991; 74: 65-83.

3. Arnett FC. Arıkylosing spondylitis. In: Koopman WJ(ed). Arthritis and allied conditions. A textbook of rheumatology. Baltimore: Williams and VVilkins 1997; 1197-1208.

4. Van der Ünden. Ankylosing spondylitis. In: Kelley WN, Harris ED, Ruddy S, Sledge CB. Texbook of Rheumatology. PhiHidelphia: W.B. Saunders Company 1997; 969-982.

5. Miyazawa N, Akiyama I. Diffuse idiopathic skeletal hyperostosis associated with risk factors for stroke. Spine 2006; 31: 225-9. [CrossRef]

6. Mader R, Novofestovski I, Adawi M, Lavi I. Metabolic syndrome and cardiovascular risk in patients with diffuse idiopathic skeletal hyperostosis. Semin Arthritis Rheum 2009; 38: 361-5. [CrossRef]

7. Aliabadi H, Biglari D, Gonzales LF, Nakaji P. Diffuse Idiopathic Skeletal Hyperostosis versus Ankylosing Spondylitis: Brief Case Review. Barrow Quarterly, 2006; 22: 4.

8. Mazières B. Diffuse idiopathic skeletal hyperostosis (Forestier-Rotes-Querol disease): what's new? Joint Bone Spine 2013; 80: 466-70. [CrossRef]

9. Eser O, Aslan A, Coşar M, Albayrak R. Yaygın İdiopatik İskelet Hiperostozu (DISH): Olgu Sunumu. Van Tip Dergisi 2006; 13: 103-5.

10. Van der Ünden. Ankylosing spondylitis. In: Kelley WN, Harris ED, Ruddy S, Sledge CB. Texbook of Rheumatology. Philedelphia: W.B. Saunders Company 1997; 969-82. 